\title{
PREDICTION OF MARTENSITE FRACTION OF MICROALLOYED STEEL BY ARTIFICIAL NEURAL NETWORKS
}

\author{
Gholamreza Khalaj, Ali Nazari ${ }^{\dagger}$ Hesam Pouraliakbar ${ }^{\ddagger}$
}

\begin{abstract}
The final microstructure and resulting mechanical properties in the linepipe steels are predominantly determined by austenite decomposition during cooling after thermomechanical and welding processes. The paper presents some results of the research connected with the development of a new approach based on the artificial neural network to predicting the martensite fraction of the phase constituents occurring in five microalloyed steels after continuous cooling. The independent variables in the model are chemical compositions, niobium condition, austenitizing temperature, initial austenite grain size and cooling rate over the temperature range of the occurrence of phase transformations. For the purpose of constructing these models, 104 different experimental data were gathered from the literature. According to the input parameters in feedforward backpropagation algorithm, the constructed networks were trained, validated and tested. In this model, the training and testing results in the artificial neural network have shown a strong potential for prediction of effects of chemical compositions and heat treatments on phase transformation of microalloyed steels.
\end{abstract}

Key words: Artificial neural network (ANN), microalloyed steel, continuous cooling, low-carbon $\mathrm{Nb}$ steel

Received: August 1, 2012

Revised and accepted: February 15, 2013

\section{Introduction}

At very high undercoolings, where bainite ceases to form, austenite transforms to martensite. Martensite has a body-centered tetragonal (BCT) crystal structure and

\footnotetext{
${ }^{*}$ Gholamreza Khalaj

Department of Engineering, Saveh Branch, Islamic Azad University, Saveh, Iran, E-mail: gh.khalaj@srbiau.ac.ir, Fax: +98 2552241501

$\dagger$ Ali Nazari

Department of Modeling and Simulation, WorldTech Scientific Research Center (WT-SRC), Tehran, Iran

${ }_{\ddagger}$ Hesam Pouraliakbar

Department of Advanced Materials, WorldTech Scientific Research Center (WT-SRC), Tehran, Iran
}

(C)ICS AS CR 2013 
is formed by a displacive mechanism which involves the cooperative movement of individual atoms. Lath martensite is the commonly occurring form in low carbon steels. As the carbon content of steel increases above $0.2 \mathrm{wt} \%$, plate (twinned) martensite tends to form. As martensitic transformation takes place at the speed of sound, the details of transformation kinetics are difficult to study. The martensite start temperature, Ms, can be determined by using the proposed empirical formulas which are based on the steel chemistry. However, one should note that Ms is known to be a function of prior austenite grain size.

The heat-affected zone is metallurgically classified into different regions, i.e. coarse-grained HAZ (CGHAZ), fine-grained HAZ (FGHAZ), intercritical HAZ (ICHAZ) and subcritical HAZ (SCHAZ) [1]. A typical variation of peak temperature in the $\mathrm{HAZ}$ for a single pass weld in conjunction with $\mathrm{Fe}-\mathrm{C}$ equilibrium phase diagram is illustrated in Fig. 1.

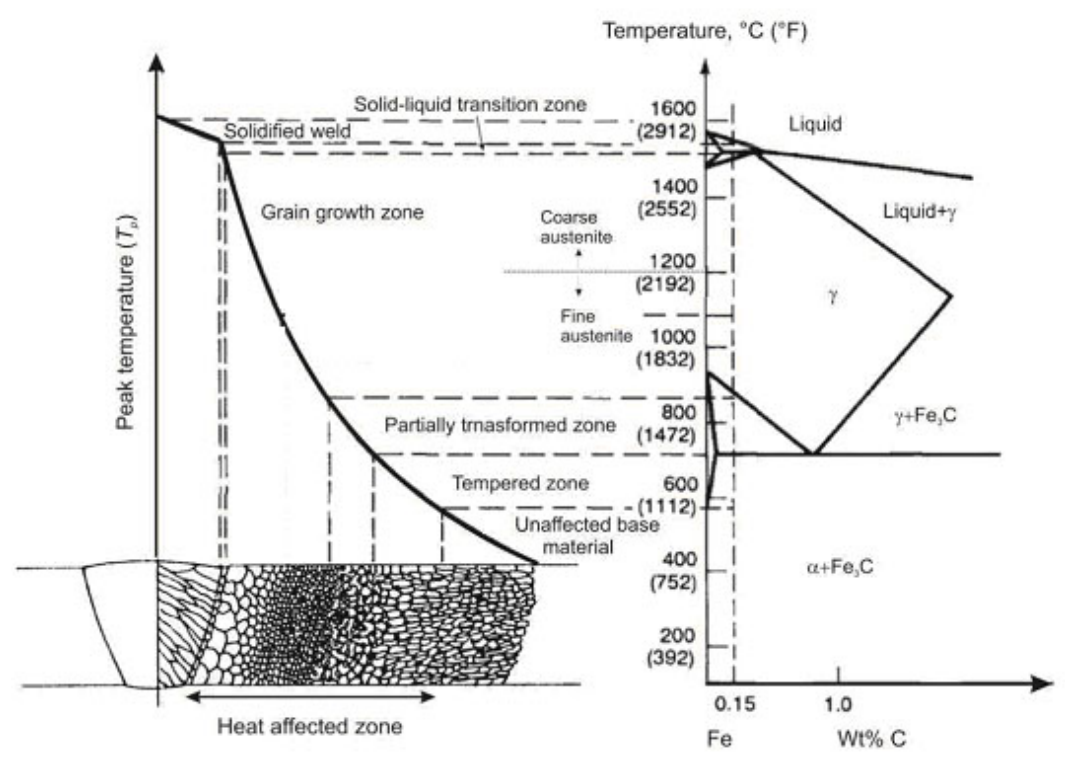

Fig. 1 Single pass weld microstructures corresponded to the peak temperatures in conjunction with $\mathrm{Fe}$ - $\mathrm{C}$ equilibrium phase diagram [1].

In brief, a full austenitization occurs in the CGHAZ followed by substantial austenite grain growth. Microalloying precipitates, which pin the austenite grain boundaries, may dissolve or coarsen in this region, allowing further grain growth of austenite. For instance, the coarsening of titanium nitride (TiN) precipitates [1] while the dissolution of niobium carbonitride $(\mathrm{Nb}(\mathrm{CN}))$ precipitates [2] have been observed at these high temperatures. Overall, due to the presence of large austenite grains in CGHAZ the formation of bainite and martensite upon cooling is favored, which deteriorates the toughness. These observations can explain why the focus of most research has been on this portion of the HAZ [1,2].

Although complete formation of austenite occurs in FGHAZ, grain growth is limited in this area due to the lower temperatures. The corresponding microstruc- 
Khalaj G. et al.: Prediction of martensite fraction of microalloyed steel...

ture typically comprises fine polygonal ferrite, which is usually associated with the high toughness [3]. Carbon-enriched austenite is partially formed in the ICHAZ. Therefore, martensite-austenite constituents, so called M/A constituents, which can initiate brittle fracture, are sometimes observed in this region [4].

Finally, due to the fact that the peak temperature is below the Ac3 in the SCHAZ, no transformation takes place in this region but a significant degree of tempering may occur [1]. In multipass welding of linepipes, additional microstructural changes may be observed, which can be due to the subsequent reheating of the lower beads. For instance, tempering of $\mathrm{M} / \mathrm{A}$ islands have been reported in the CGHAZ of multipass welds [5]. From mechanical properties point of view, it is noteworthy to mention that the lower toughness of the intercritically reheated CGHAZ has been the subject of several investigations, see for example [6].

Artificial neural networks (ANNs) are a family of massively parallel architectures that solve difficult problems via the cooperation of highly interconnected but simple computing elements (or artificial neurons). Basically, the processing elements of a neural network are analogous to the neurons in the brain which consist of many simple computational elements arranged in several layers [7]. ANNs have been applied for prediction different properties of different type of steels in the previous works [8-10].

In authors' previous work $[11,12]$ the effects of chemical composition, austenitizing temperature, $\mathrm{Nb}$ in solution, austenitic grain size and cooling rate on Vickers microhardness and ferrite fraction of microalloy steels were modeled with ANNs. According to the authors' literature survey, there is no work investigating the effects of chemical compositions, austenitizing temperature, $\mathrm{Nb}$ in solution, austenite grain size and cooling rate on martensite fraction of microalloy steels.

The objective of the present work is to describe the austenite to martensite phase transformation behavior of the five HSLA steels under continuous cooling conditions in the cooling rates regime of " $0.3-198^{\circ} \mathrm{C} / \mathrm{s}$ " with various initial austenite grain structures and different austenitizing temperatures. All in all, 104 martensite fraction data were collected from the literature, trained, tested and validated by neural network. The obtained results were compared with experimental ones to evaluate the software power for predicting the effects of mentioned parameters on martensite fraction of the studied steels.

\section{Artificial Neural Networks}

An artificial neural network (ANN) is a massively parallel, distributed information processing structure consisting of processing elements and many interconnections called connection weights between them. It resembles the brain in two respects; knowledge is acquired by the network through a learning process and interneuron connection weights, known as synaptic weights, are used to store the knowledge [7]. An artificial neuron is composed of five main parts: inputs, weights, sum function, activation function and outputs. Inputs are information that enters the neuron from other neurons from external world. Weights are values that express the outcome of an input set or another process element in the preceding layer on this process element. Sum function is a function that calculates the effect of inputs and weights completely on this process element. This function computes the net 
input that approaches to a neuron. The weighted sums of the input components $(\text { net })_{j}$ are calculated using Eq. (1) as follows [13]:

$$
(n e t)_{j}=\left(\sum_{i=1}^{n} w_{i j} x_{i}\right)+b,
$$

where $(n e t)_{j}$ is the weighted sum of the $j$ th neuron for the input received from the preceding layer with n neurons, $W_{i j}$ is the weight between the $j$ th neuron in the previous layer, $x_{i}$ is the output of the $i$ th neuron in the previous layer [13]. $b$ is a fix value as an internal addition, and $\sum$ represents sum function. Activation function is a function that processes the net input obtained from sum function and determines the neuron output. In general, for multilayer feed-forward models as the activation function sigmoid activation function is used. The output of the $j$ th neuron $(o u t)_{j}$ is computed using Eq. (2) with a sigmoid activation function as follows [13]:

$$
O_{j}=f(n e t)_{j}=\frac{1}{1+e^{-\alpha(n e t)_{j}}},
$$

where $\alpha$ is constant used to control the slope of the semi-linear region. The sigmoid nonlinearity activates in every layer except in the input layer. The sigmoid activation function represented by Eq. (2) gives outputs in $(0,1)$. If desired, the outputs of this function can be adjusted to $(-1,1)$ interval. As the sigmoid processor represents a continuous function, it is particularly used in nonlinear descriptions. Because its derivatives can be determined easily with regard to the parameters within $(n e t)_{j}$ variable [13].

An ANN is a combination of the processing elements linked to each other with connection weights. The processing elements called neurons are arranged in layers and constitute the network architecture. Multilayer network models are classified as feedforward networks. The basic structure of a multilayer feedforward network model can be determined as consist of an input layer, one or more hidden layer and an output layer. The input layer neurons receive input patterns from the external environment and propagate them on to the first hidden layer neurons. In this layer, any data processing is not carried out. Input values distributed from each of the input layer neurons are multiplied by each of the adjustable connection weights linking the input layer neurons to hidden layer neurons. At each neuron in the hidden layer, weighted input values are summed and a bias value is added. Then combined input value is passed through a nonlinear transfer function like sigmoid or hyperbolic tangent to obtain the output value of the neuron. This output value is an input for the neurons situated in the following layer. Finally, the output layer neurons produce the output value of the network model [7].

Determining an appropriate architecture of a neural network for a particular problem is an important issue, since the network topology directly affects its computational complexity and its generalization capability. Multilayer feedforward network models with one hidden layer can approximate any complex nonlinear function provided sufficiently many hidden layer neurons are available. Therefore, in this study, multilayer feedforward network models containing one hidden layer were used. Determination of optimum number of the hidden layer neurons is very important in order to predict accurately a parameter using by ANNs. But there is 
Khalaj G. et al.: Prediction of martensite fraction of microalloyed steel...

no theory how many hidden layer neuron need to be used for a particular problem. The best approach to find the optimum number of hidden neurons is to start with a few numbers of neurons and then slightly increasing the number of neurons. During this process for each hidden neuron number the performances of the network models are monitored according to chosen performance criteria [7].

A typical neural network consisted of input, sum function, log-sigmoid activation function and output [13]. This typical neural network is reinforced with an advanced training algorithm named as Levenberg-Marquardt backpropagation. The input values to a neuron are obtained by multiplying the output of the connected neuron by the synaptic strength of the connection between them. In this paper, Levenberg-Marquardt backpropagation (LMBP) algorithm is utilized as training algorithm instead of commonly used standard BP method for its robustness in the computing process [14].

\section{Data Collection}

In the present investigation, the artificial neural network has been trained, tested and validated for prediction martensite fraction of HSLA steels. For this purpose, the experimental data of five HSLA steels with different chemical compositions have been used [15-19]. The chemical compositions of these steels are summarized in Tab. I. The input variables of the ANN modeling are the weight percent of alloying elements, austenitizing temperature, $\mathrm{Nb}$ in solution, austenite grain size and cooling rate. These parameters along with their ranges have been summarized in Tab. II.

Employing appropriate thermal cycles, continuous cooling transformation (CCT) tests were conducted to examine the effect of chemical compositions, niobium condition, austenitizing temperature, austenite grain size and cooling rate on austenite decomposition behavior of the steels. The resulting microstructures, which usually consist of ferrite, bainite and martensite-austenite (MA) constituents, were examined using optical microscopy. They were revealed using appropriate etchants and the corresponding phase volume fractions were subsequently measured in accordance with ASTM standards. To consider the significant effect of the niobium solid solution level on the transformation of austenite, two thermal histories were developed. For the first case, $\mathrm{Nb}$ was dissolved in solid solution prior to austenite decomposition. In contrast, the second scenario involved the formation of $\mathrm{Nb}(\mathrm{C}, \mathrm{N})$ precipitates prior to austenite decomposition, i.e. leaving a low level of $\mathrm{Nb}$ in solid solution.

\section{Artificial Neural Networks Parameters and Structure}

ANN model in this research has sixteen neurons in the input layer and one neurons in the output layer as demonstrated in Fig. 2. The values for input layers were carbon weight percent $(\mathrm{C})$, manganese weight percent $(\mathrm{Mn})$, niobium weight percent $(\mathrm{Nb})$, molybdenum weight percent (Mo), titanium weight percent ( $\mathrm{Ti}$ ), 

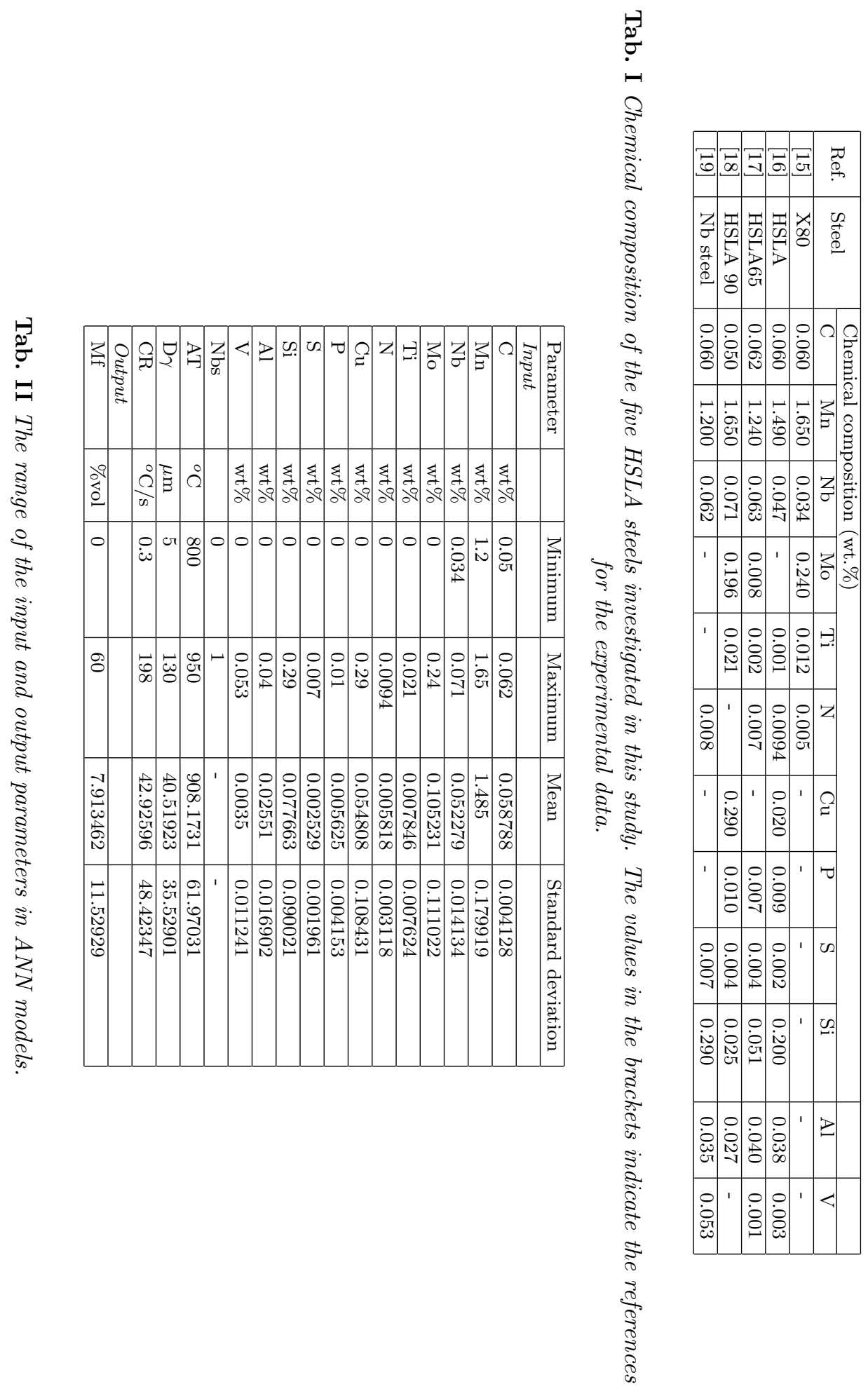
Khalaj G. et al.: Prediction of martensite fraction of microalloyed steel...

nitrogen weight percent $(\mathrm{N})$, copper weight percent $(\mathrm{Cu})$, phosphorous weight percent $(\mathrm{P})$, sulfur weight percent $(\mathrm{S})$, silicon weight percent $(\mathrm{Si})$, aluminum weight percent $(\mathrm{Al})$, vanadium weight percent $(\mathrm{V}), \mathrm{Nb}$ in solution (Nbs), austenitizing temperature $(\mathrm{AT})$, the initial austenite grain size $(\mathrm{D} \gamma)$ and the cooling rate $(\mathrm{CR})$.

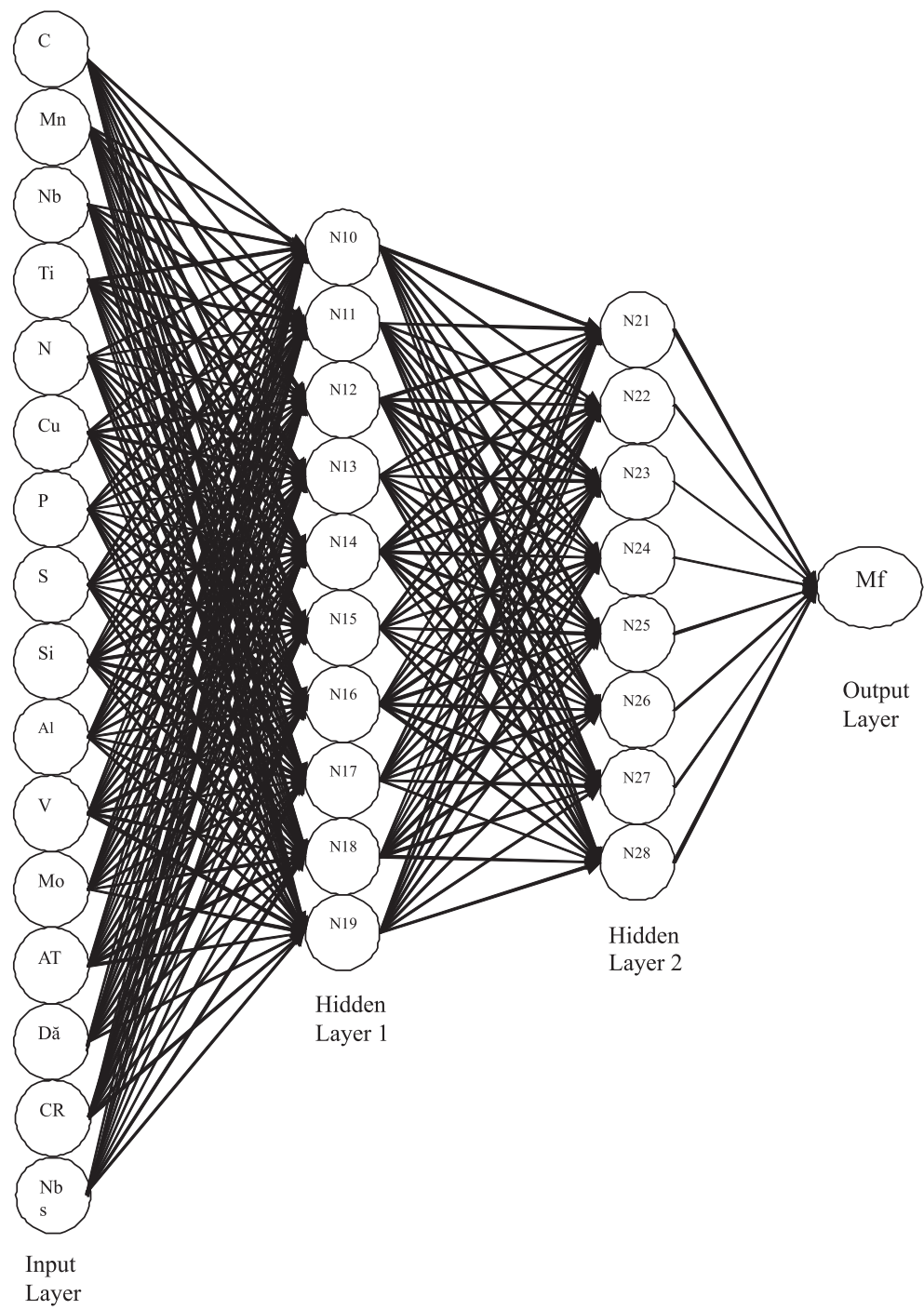

Fig. 2 The system used in the ANN model.

The value for output layer was martensite fraction (Mf). The range of the input and output parameters has been illustrated in Tab. II. Two hidden layer with ten and eight neurons were used in the architecture of multilayer neural network because of its minimum absolute percentage error values for training and testing sets. The neurons of neighboring layers are completely interconnected by weights. Finally, the output layer neurons produce the network prediction as a result. 
In this study, the backpropagation training algorithm has been utilized in feedforward two hidden layers. Backpropagation algorithm, as one of the most wellknown training algorithms for the multilayer perceptron, is a gradient descent technique to minimize the error for a particular training pattern in which it adjusts the weights by a small amount at a time [20]. The non-linear sigmoid activation function was used in the hidden layer and the neuron outputs at the output layer. Momentum rate and learning rate values were determined and the model was trained through iterations. The trained model was only tested with the input values and the predicted results were close to experiment results. The values of parameters used in neural network model are given in Tab. III.

\begin{tabular}{|l|l|}
\hline Parameters & ANN \\
\hline Number of input layer units & 16 \\
\hline Number of hidden layer & 2 \\
\hline Number of first hidden layer units & 10 \\
\hline Number of second hidden layer units & 8 \\
\hline Number of output layer units & 1 \\
\hline Momentum rate & 0.87 \\
\hline Learning rate & 0.75 \\
\hline Error after learning & 0.000055 \\
\hline Learning cycle & 30.000 \\
\hline
\end{tabular}

Tab. III The values of parameters used in neural network model.

A total of 104 data of continuous cooling tests in different conditions were collected, trained, validated and tested by means of ANNs. Among 104 experimental sets, 74 sets were randomly chosen as a training set for the ANN modeling, 15 data for validating the results and the remaining 15 sets were used as testing the generalization capacity of the proposed models.

The performance of an ANN model mainly depends on the network architecture and parameter settings. One of the most difficult tasks in ANN studies is to find this optimal network architecture, which is based on the determination of numbers of optimal layers and neurons in the hidden layers by a trial and error approach. The assignment of initial weights and other related parameters may also influence the performance of the ANN to a great extent. However, there is no well defined rule or procedure to have an optimal network architecture and parameter settings where the trial and error method still remains valid. This process is very timeconsuming [21].

In this study, the Matlab ANN toolbox is used for ANN applications. To overcome optimization difficulty, a program has been developed in Matlab which handles the trial and error process automatically [21]. The program tries various numbers of layers and neurons in the hidden layers both for the first and second hidden layers when the highest RMSE (Root Mean Squared Error) of the testing set, as the training of the testing set is achieved [21]. 
Khalaj G. et al.: Prediction of martensite fraction of microalloyed steel...

\section{Results and Discussion}

In this study, the error arose during the training, validating and testing in ANN model can be expressed as absolute fraction of variance $\left(\mathrm{R}^{2}\right)$ which was calculated by Eq. (3) [22]:

$$
\mathrm{R}^{2}=1-\left(\frac{\Sigma_{i}\left(t_{i}-o_{i}\right)^{2}}{\Sigma_{i}\left(o_{i}\right)^{2}}\right),
$$

where $t$ is the target value and $o$ is the output value.

All of the results obtained from experimental studies and predicted by using the training, validation and testing results of ANN model are given in Figs. 3a, 3b and $3 \mathrm{c}$, respectively. The linear least square fit line, its equation and the $\mathrm{R}^{2}$ values have been shown in these figures for the training, validation and testing data. Also, inputs values and experimental results with validation and testing obtained from ANN model were given in Tabs. IV and V, respectively. As it is visible in Fig. 3 , the values obtained from the training, validation and testing in ANN model are very close to the experimental results. The result of testing phase in Fig. 3 shows that the ANN models are capable of generalizing between input and output variables with reasonably good predictions.

Traditional regression analysis was made with MINITABß). The regression equation is:

$\mathrm{Mf}=281-4512 \mathrm{C}-21.9 \mathrm{Mn}-1227 \mathrm{Nb}-129 \mathrm{Mo}-5.43 \mathrm{Nbs}+0.104 \mathrm{AT}+$ $0.0835 \mathrm{D} \gamma+0.129 \mathrm{CR}$

The $\mathrm{R}^{2}$ value is 0.461 .

The performance of the ANN model is shown in Fig. 3. The best value of $\mathrm{R}^{2}$ is 0.98927 for testing set. The minimum values of $\mathrm{R}^{2}$ are 0.9856 for training set. All of $\mathrm{R}^{2}$ values show that the proposed ANN models are suitable and can predict the martensite fraction values very close to the experimental values. Statistical parameters of training, validation and testing sets of the ANN models are presented in Tab. VI.

\section{Conclusions}

An artificial neural-network model was developed to model and predict the martensite fraction of low carbon microalloyed steels. Experiments and models were conducted on linepipe steels to investigate the effect of chemical compositions, cooling rate, austenitizing temperature, austenite grain size and niobium level on decomposition behavior of austenite to martensite. In addition to the well-established dependence of transformation products on austenite grain size and cooling rate, current study shows a remarkable effect of $\mathrm{Nb}$ state on austenite decomposition to martensite.

The ANN approach appears to be a very powerful tool in materials engineering. The results presented show that the prediction of the microstructures of the considered steel is in good agreement with the experimental data. The ANN was 


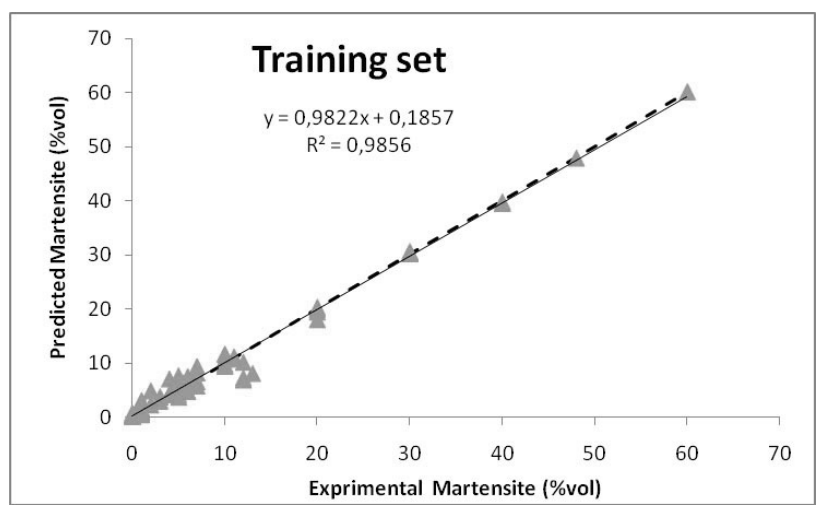

(a)

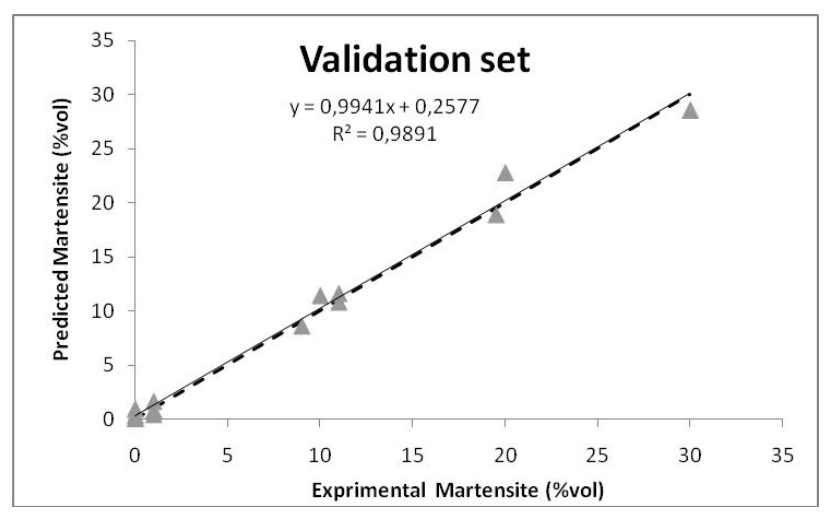

(b)

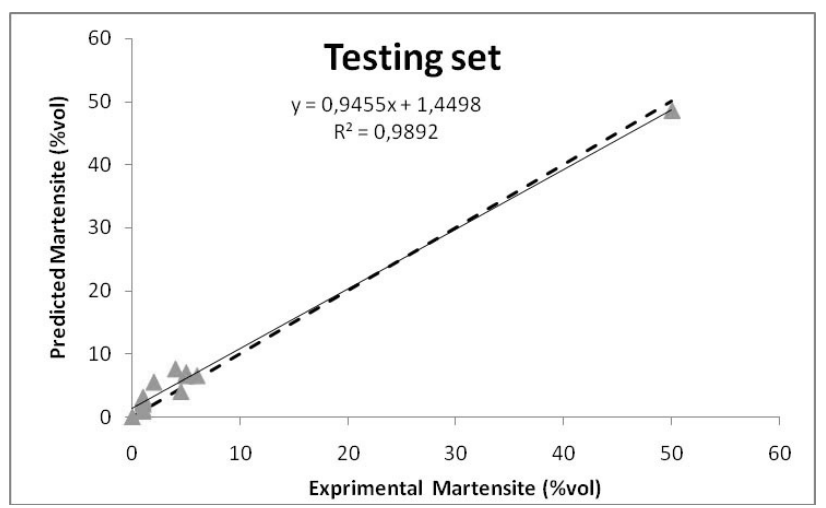

(c)

Fig. 3 The correlation of the measured and predicted martensite fraction values of HSLA steels in a) training, b) validation and c) testing phase for ANN models. 
Khalaj G. et al.: Prediction of martensite fraction of microalloyed steel...

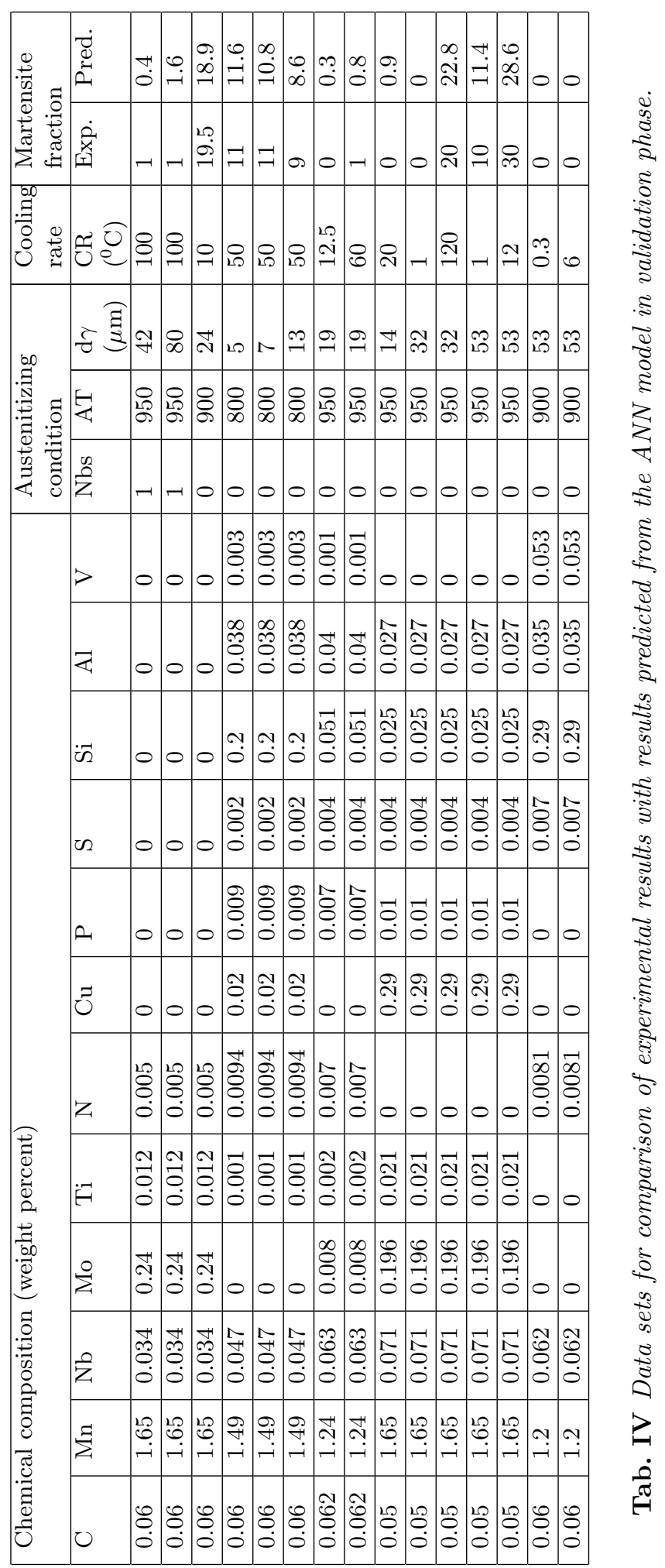


Neural Network World 2/13, 117-130

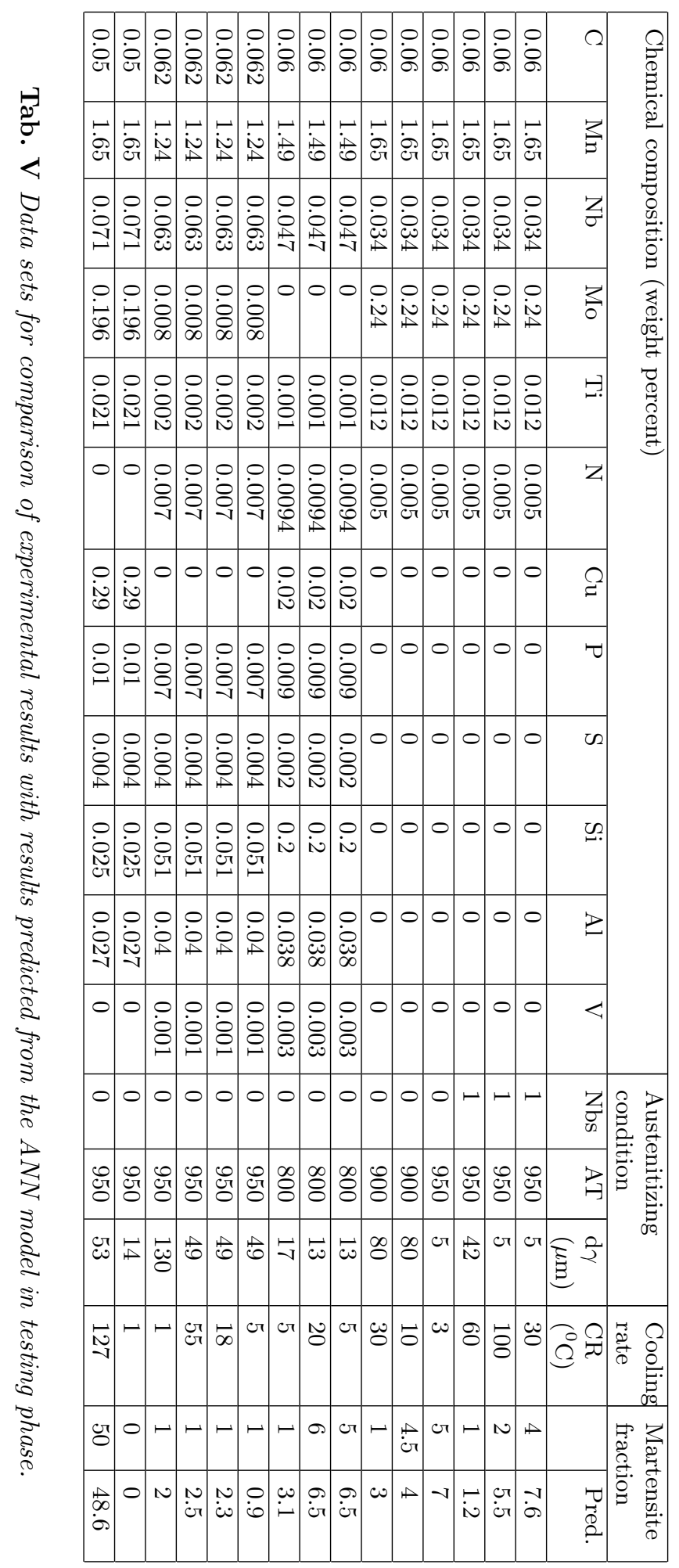


Khalaj G. et al.: Prediction of martensite fraction of microalloyed steel...

trained, tested and validated on the data obtained from the literature. The accuracy of values evaluated by the ANN model is much higher than that obtained from calculations using the classical, experimental models. This means that the well-trained network under laboratory conditions is able to predict the correct values of the output parameters of the industrial process. ANN models will be valid within the ranges of variables.

\begin{tabular}{|l|l|l|l|l|l|}
\hline & RMSE & SSE & MSE & MAPE(\%) & P-value \\
\hline train & 1.41 & 146.32 & 1.98 & 41.7 & 0.6788 \\
\hline validate & 0.98 & 14.34 & 0.96 & 91.6 & 0.8379 \\
\hline test & 1.78 & 47.32 & 3.15 & 72.7 & 0.9973 \\
\hline
\end{tabular}

Tab. VI Statistical parameters of the proposed ANN models.

Root Mean Squared Error

$$
R M S E=\left[\frac{\sum(X-Y)^{2}}{n}\right]^{1 / 2}
$$

Mean Absolute Percentage Error

$$
M A P E=\frac{\left|\frac{X-Y}{Y}\right| \times 100}{n}
$$

Mean Squared Error

$$
M S E=\frac{\sum(X-Y)^{2}}{n}
$$

Sum Squared Error

$$
S S E=\sum(X-Y)^{2}
$$

where $n=$ total number of pairs $\mathrm{X}$ and $\mathrm{Y}$ values. $\mathrm{X}$ is the target value and $\mathrm{Y}$ is the output value.

\section{References}

[1] Grong O.: Metallurgical Modelling of Welding. Maney Publishing, 2nd edition ed., 1997.

[2] Easterling K.: Introduction to the Physical Metallurgy of Welding. Butterworth Heinemann, 1992.

[3] Palmiere E. J., Garcia C. I., Ardo A. J.: Compositional and microstructural changes which attend reheating and grain coarsening in steels containing niobium, Metallurgical and Materials Transactions A, 25, 2, 1994, pp. 277-286.

[4] Lee S., Kim B. C., Kwon D.: Correlation of microstructure and fracture properties in weld heat-affected zones of thermomechanically controlled processed steels, Metallurgical Transactions A, 23, 10, 1992, pp. 2803-2816. 
[5] Svensson L.-E.: Control of microstructures and properties in steel arc welds. CRC Press, 1994.

[6] Chen Y., Guo A., Wu L., Zeng J., Li P.: Microstructure and mechanical property development in the simulated heat affected zone of V treated HSLA steels, Acta Metallurgica Sinica (English Letters), 19, 1, 2006, pp. 57-67.

[7] Ozcan F., Atis C. D., Karahan O., Uncuoglu E., Tanyildizi H.: Comparison of artificial neural network and fuzzy logic models for prediction of long-term compressive strength of silica fume concrete. Advances in Engineering Software, 40, 9, 2009, pp. 856-863.

[8] Sterjovski Z., Nolan D., Carpenter K. R., Dunne D. P., Norrish J.: Artificial neural networks for modelling the mechanical properties of steels in various applications, Journal of Materials Processing Technology, 170, 2005, pp. 536-544.

[9] Tan Wen, Liu Zhen-Yu, Wu Di, Wang Guo-Dong: Artificial Neural Network Modeling of Microstructure During C-Mn and HSLA Plate Rolling, Journal of Iron and Steel Research, International. 16, (2), 2009, pp. 80-83.

[10] Jiajun Wang, Pieter J. Van Der Wolk, Sybrand Van Der Zwaag: Effects of Carbon Concentration and Cooling Rate on Continuous Cooling Transformations Predicted by Artificial Neural Network, ISIJ International, 39, 10, 1999, pp. 1038-1046.

[11] Khalaj G., Yoozbashizadeh H., Khodabandeh A., Nazari A.: Artificial neural network to predict the effect of heat treatments on Vickers microhardness of low- carbon $\mathrm{Nb}$ microalloyed steels. Neural Comput. Appl., 2011, doi:10.1007/s00521-011-0779-z

[12] Khalaj G., Khoeini M., Khakian-Qomi M.: ANN-based Prediction of ferrite fraction in continuous cooling of microalloyed steels, Neural Computing and Applications, 2012, doi: 10.1007/s00521-012-0992-4.

[13] Sarıdemir M., Topcu I. B., Ozcan F., Severcan M. H.: Prediction of long-term effects of GGBFS on compressive strength of concrete by artificial neural networks and fuzzy logic, Construction and Building Materials, 23, 2009, pp. 1279-1286.

[14] Sobhani J., Najimi M., Pourkhorshidi A. R., Parhizkar T.: Prediction of the compressive strength of no-slump concrete: A comparative study of regression, neural network and ANFIS models, Construction and Building Materials, 24, 2010, pp. 709-718.

[15] Tafteh R.: Austenite decomposition in an X80 linepipe steel. Master's thesis, The University of British Columbia, 2011.

[16] Gerami S.: Characterization and microstructural evolution model of a Nb complex phase steel. Master's thesis, The University of British Columbia, 2010.

[17] Petkov P.: Austenite decomposition of low carbon high strength steels during continuous cooling. Master's thesis, The University of British Columbia, 2004.

[18] Lottey K. K.: Austenite decomposition of a HSLA-Nb,Ti steel and an A1-TRIP steel during continuous cooling. Master's thesis, The University of British Columbia, 2002.

[19] Olasolo M., Uranga P., Rodriguez-Ibabe J. M., López B.: Effect of austenite microstructure and cooling rate on transformation characteristics in a low carbon $\mathrm{Nb}-\mathrm{V}$ microalloyed steel. Mater. Sci. Eng. A, 528, 2011, pp. 2559-2569.

[20] Suratgar A. A., Tavakoli M. B., Hoseinabadi A.: Modified Levenberg-Marquardt method for neural networks training. World Acad. Sci. Eng. Technol., 6, 2005, pp. 46-48.

[21] Guzelbey I. H., Cevik A., Erklig A.: Prediction of web crippling strength of cold-formed steel sheetings using neural Networks, J. Constr. Steel Res., 62, 2006, pp. 962-973.

[22] Lobato J., Canizares P., Rodrigo M. A., Piuleac C. G., Curteanu S., Linares J. J.: Direct and inverse neural networks modelling applied to study the influence of the gas diffusion layer properties on PBI-based PEM fuel cells, International Journal of Hydrogen Energy, 35, 2010, pp. $7889-7897$. 